\section{Saúde mental e trabalho: os problemas que persistem}

Mental health and work: persistent issues
Leny Sa to 1

Márcia Hespanhol Bernardo 2

\begin{abstract}
This article focuses on Mental Health and Work as a subarea of the Workers' Health field. Its starting point is the observation that the probl ems of mental health rel a ted to wo rk iden tified in the mid 80's still persist. After exposing the taxonomy of these problems, the paper searches to explain some of their current expressions from the assistance and the surveillance in wo rkers' health as well as from the point of view of some trade unions more atten tive to this issue. In ord er to do that, the Cen tro de Referência em Saúde do Trabalhador (CRST) of Campinas is taken as a reference. Finally, it points out to some characteristics of work in the present context to understand the reasons of this persistence.

Key words Workers' health, Mental health and work, Worker's health policies, Social psychology of health
\end{abstract}

Resumo Este artigo toma por objeto a Saúde Mental e Tra balho como uma subá rea do campo da Saúde do Trabalhador. Parte da constatação de que os problemas de saúde mental e trabalho, já identificados em meados da década de 1980, persistem. Após retomar a taxonomia de tais problemas, busca evidenciar algumas de suas expressões atuais a pa rtir da assistência e da vigilância em saúde do trabalhador, bem como pela perspectiva de alguns sindicatos mais aten tos à questão. Para tal, toma como ponto de partida o Centro de Referência em Saúde do Trabalhador (CRST) de Campinas. Por fim, po n tua algumas cara cter ís ticas do trabalho no contexto atual para compreender as motivações dessa persistência.

Palavras-ch ave Saúde do trabalhador, Saúde mental e trabalho, Politicas de saúde do trabalhador, Psicologia social da saúde

${ }^{1}$ Instituto de Psicologia

da Un iversidade de

São Paulo, Departamen to

de Psicologia Social e

do Trabalho.

Av. Profess or Mello Moraes

1.721, 05508-900,

São Paulo SP.

lenysato@usp.br

2 Cen tro de Referência

de Saúde do Trabalhador

de Campinas. 


\section{Introdução}

Como o título do arti go anuncia, recon hece-se que a temática da Saúde Mental e Trabalho, no Brasil já tem um bom caminho percorrido, e muitos dos problemas que impulsionaram o desenvolvimen to dessa área persistem. Sob a designação Saúde Mental e Trabalho, temos, desde o início da década de 1980, no Brasil, diversos estudos, pe squisas e atividades de intervenção a partir dos serviços públi cos de saúde e das entidades sindicais, conformando o que se poderia den ominar de uma subá reado campo da Saúde do Trabalhador. O fato de estabel ecermos esse corte temporal não significa que an tes desse período não se desenvolve ss ematividades focalizandoa saúde mental de pessoas que trabalhassem. É bom notar que, desde a década de 1920, nos Estados Uni dos da América, documentam-se atividades englobadas sob o título de Saúde Mental Ocupaci onal (Shartle, 1950) que, como prática, privilegi ava a oferta de assistência psicoterápica aos trabalhadores sen do o trabalho, suas condições e sua organização, tomados apenas como pano de fundo dos problemas que demandavam essa assistência. Cálculos de custo - ben efício eram fortes argumentos para a oferta de psicoterapia.

No Brasil, por seu turno, as denominadas "ciências do comportamen to", na década de 1940 também se ocupavam da saúde mental das pessoas que trabalhavam. Bertolli-Filho (19921993) mostra como a medicina, ocupando-se da esfera psicológica atuava em dois domínios: o primei ro que congregava a construção e a aplicação de técnicas visando à seleção e à adaptação profissional dos trabalhadores (a psicotécnica), e a segunda, que se dava através da análise de operários que apresen tavam possiveis "transtornos mentais", causadores ou resultantes de acidentes que comprometiam a existência do indivíduo e dos companheiros de labuta. Neste segundo domínio, os profissionais de saúde mental eram recrutados para atuarem como peritos para a Justiça do Trabalho, com vistas a subsidiar sua decisão nos casos de pedidos de in denização enca minh ados pelos trabalhadores acidentados. Aqui, tanto a psicanálise como o paradigma organicista foram adotados como a poios para a emissão desses laudos. Observase que, apesar de tomarem leituras teóricas bastante distintas, as conclusões convergiam para o mesmo diagnóstico: ... existência de traumatismos fisicos [ provoc ados pelo acidente] favo recedores do desenvolvimento de "neuroses de respon- sabilização" dos patrões pelo acidente de trabalho, sentimen to rotulado pela med icina como " $s-$ nistrose", "neurose de renda", "neurose de desejo" e "indenizofilia” (Bertolli-Filho, 1992-1993). Esses diagnósti cos sustentavam, então, a con clusão de que os trabalhadores acidentados eram "simuladore s" e, assim, buscavam ex torquir as companhias seguradoras.

Tan to a denominada saúde mental ocupacional como as ciências do comporta men to bu scam a gênese dos problemas de saúde mental dos trabalhadores no universo intra-individual, sen do o trabalho, suas condições e sua or ga nização mero pano de fundo. Assim, ao abstrair as condições concretas de trabalho e, principalmen te, as relações de trabalho, contribuíram para con s truir a explicação que "culpabiliza a vítima".

De modo distinto, ao estar abrigada no campo da Sa ú de do Trabalhador, a Saú de Mental e Trabalho toma as relações de trabalho e sua historicidade como matriz de leitura, con forme a formulação da Saúde Coletiva descrita por Lacaz (1996; 1997) e Min ayo - Gomez \& ThedimCosta (1997).

Como já extensamen te apres en tado por Seligmann-Silva (1986; 1994), a Saúde Mental no Trabalho, como campo de investigação e de práticas, tem acolhido diferen tes corren tes teórico-metodoló gicas, construin do diversos objetos de investigação. Tem-se desde as abordagens sustentadas na teoria do estresse até as que orientam suas leituras pela psicanálise em seus vários matizes. Como não deixaria de ocorrer aqui também, as ciências que focalizam o mundo psicológico a partir de distintos objetos ( com portamen to, sofrimen to, subjetividade, imaginário/simbólico, doença mental) têm suas vinculações tanto com a Biologia como com as Ciências Sociais (Antropologia, Sociologia, Lingüística), fazen do com que múltiplos "nomes" sejam utilizados para se referir à Saúde Mental e Trabalho.

Inevitável, então que, no mais das vezes, n em sem pre se con si ga en t a bular diálogo en tre as diversas abordagens, como constatam Figueiredo \& Santi (2000) e Figuei redo (2002) a respeito da psicologia, o que se mostra pertinen te também para o caso que aqui se discute. Qualqu er leva nta men to das pe s quisas desenvo lvidas no Brasil, de teses, dissertações e artigos, evidenciará que essa multiplicidade de orientações en contra abri go em gru pos e linhas de pesquisa sediados em universidades no Brasil.

Se, no âmbito acadêmico, o debate pode priorizar a dimensão teórico-metodológica de 
cada uma das abordagens, no âmbi to dos serviços públicos de saúde e das entidades sindicais, ele tem se de senvo lvi do em torno, prioritariamente, do alcance de respostas que considerem a diversidade da realidade vivida pelos trabalhadores e a premência em compreen der, lidar e modificar as condições que geram os problemas de saúde mental. A diversidade de situações apresentadas pela realidade cotidianamen te por eles vivida não re s peita as fron teiras teó rico-metodológicas. Assim, para além do deb a te - importante, di ga-se de passagem - em torno das teorias e dos métodos mais adequados para compreender, interpretar ou explicar os fenômenos de Saúde Mental e Trabalho, busca-se outro ti po de resposta: em que medida esses olhares poderão subsidiar ações práticas, individuais e coletivas, que considerem o a pa ra to institu cional e legal que en qu ad ram as relações de trabalho no Brasil? E, além disso, em que medida, as opções teóricas tomadas poderão nos levar a angariar elemen tos para in tervir na realidade? Os probl emas de ordem prá tica que se apres entam também exi gem que outras questões, como direitos trabalhistas e previdenciários, se imponham e demandem a a tenção dos prof is si onais de saúde.

O que se verifica nessa trajetória de cerca de duas décadas da Saúde Mental e Trabalho no Brasil é que alguns grupos de probl emas fora $m$ se conformando, a partir da acolhida das demandas aos serviços públi cos de Saú de do Trabalhador e às entidades sindicais. Importante ressaltar que, dada a origem mesma do Movim en to de Sa ú de do Trabalhador no Brasil (Sato, Lacaz \& Bernardo, 2004; Ribei ro et al., 2002), foi a realidade de trabalho urbano, sob regulamentação da CLT, aqu ela que, de início, foi tomada como foco de atenção. Desta feita, os probl emas identific ados são aqueles que trab alh adores e lideranças sindicais inseri dos nesse contex to trazem aos serviços públicos de Saúde do Trabalhador e às entidades de assessoria sindical, como, por exemplo, o DIESAT (Departamen to In tersindical de Estu dos e Pesquisas de Saúde e dos Ambientes de Trabalho).

In depen den tem en te do aporte teórico-metodológi co adotado para o exame das relações en tre a saúde mental e o trabalho, recon hece-se que um ponto de partida importante para o exame detido por parte dos profissionais de saúde, de determinados problemas de saúde, bem como os recortes operado s, é dado pela vivência, ex periência e conhecimen to dos trabalhadores sobre o seu dia-a-dia de trabalho; ou, se se preferir, a terminologia empregada por Oddone et al. (1986): o conhecimen to e a subjetividade operária. A interação cotidiana no local de trabalho e em outros espaços de sociabilidade, a vivência pessoal e singular e a troca de informações animam a construção, pelos trabalhadores, de conhecim en tos e explicações sobre a relação saúde mental e trabalho.

Foi a partir do acolhimen to às demandas aos serviços públicos de saúde e às entidades sindicais que alguns grupos de probl emas vieram a con formar essa subárea de Sa ú de Mental e Trabalho. Podemos acom odá-los em cinco grupos, con forme Sa to \& Seligmann-Silva (1986) e Sa to (1996): o primei ro diz respei to àdássica relação entre saúde mental e organização do processo de trabalho. Aqui foram importantes os estudos no setor de serviços e no setor industrial, nos quais a organização do trabalho tayl orista-fordista foi bastante estudada. O segundo se refere aos efeitos neu ropsicológicos decorren tes da exposição a solven tes e metais pesados, para cujo equacion a men to, a atuação multidisciplinar foi ex trem a m en te importante, ten do os profissionais da área "psi" um papel bastanterel evante no sen ti do de con tri buir para o diagnóstico precoce da intoxicação (Rebouças et al., 1989). O tercei ro grupo tem as repercussões psicossociais decorren tes dos acidentes de trabalho e de doenças do trabalho e profissionais como foco, em que as Lesões por Esforços Repeti tivos são um importante exemplo. Outra família de problemas congrega os relacionados ao sofrimento psíqui co que pode estar associado ao fato de os trabalhadores enfrentarem cotidianamente situações de ris co à vida, como as explosões e o trabalho em altu ra. Por fim, como apontado por Seligmann-Silva (1997), as situações de de s em prego pro lon gado em suas repercussões psicossociais.

Importante lembrar que uma taxon omia é sem pre uma dentre várias possíveis e, por isso, arrisca separar fenômenos que deveriam estar numa mesma categoria e englobar numa única os que poderiam estar separados. Corren do esse ris co, a opção aqui adotada foi norteada para apres entar gru pos de probl emas que se movimentaram dos locais de trabalho para as entidades sindicais, para os serviços públ i cos de saúde e para as insti tuições de pesquisa e universidade. 


\section{A expressão atual dos probl emas de saúde mental e trabalho}

Para apres entar como os problemas de saúde mental e trabalho hoje se expressam, opta-se por tomar o caso de um serviço público de Saú de do Trabalhador, o Centro de Referência em Saúde do Trabalhador (CRST) de Campinas, como local de pon to de partida para a discussão aqui desenvo lvida.

Com esse intuito, primeiramente, s erão estudados os probl emas que configura ram a área de Saúde Mental e Trabalho - nas condições acima apontadas - buscandodiscutir as formas como eles se apresentam na demanda por assistência em Saúde do Trabalhador. Em seguida, as questões de Saúde Mental e Trabalho serão analisadas à luz da percepção dos sindicatos e dos profissionais de saúde que realizam a tividades de vigilância em ambientes e proce ssos de trabalho.

\section{A saúde mental vista pela assistência ao trabalhador}

Quando se observa o que há de novo e o que persiste tomando-se a assistência à saúde mental dos trabalhadores, nota-se que as "novidades" não dizem re spei to a uma maior ênfase dada a esse tipo de probl ema nos serviços de saúde, n em a um aumento expressivo de notificações de problemas de saúde mental, mas, sim, a inclusão de novas ocupações en tre aqu elas que, mais freqü en temente, têm sido associadas às qu eixas relaci on adas à esfera psíquica.

O que se observa no CRST de Campinas é que o número de notificações de probl emas de saúde mental relacion ados ao trabalho ainda é pouco significativo em relação ao total dos atendimentos, fato que parece também ocorrer em outros serviços do mesmo tipo. No ano de 2004, por exem plo, os "transtornos psíqui co s" - mais especificamente, a depressão não-orgânica, o estresse e os transtornos do sono - representaram menos de 1\% dos 892 diagnósticos médicos atribuídos a novos pacien tes desse s erviço, enquanto as LER correspon deram a quase 70\% desse total (CRST-Campinas, 2004). Considerou-se, aqui, apenas os diagnósticos principais atribuídos com base naClassificação In tern aci onal de Doenças (CID 10).

Por outro lado, o número pou co significativo desses diagnósti cos não indica necessariamen te sua baixa freqüência na população trabalh adora. Antes, p a recem mostrar a persistên- cia da dificuldade por parte de todos os envolvi dos - em presas, profissionais de saúde e peritos do INSS - em reconh ecer o trabalho como ca us ador de probl emas de saúde mental, o que, conseqü en temente, reduz a busca de ajuda em serviços dereferên cia, como os CRSTs.

Apesar de os probl emas de Saúde Mental e Trabalho serem recon hecidos na CID 10, a sua notificação ainda repre s enta um desafio para a saúde pública. A lógica positivista hegemônica e a visão de que a gênese desses probl emas re side na esfera intra-indivi dual - também fortemente presente nos campos previdenciário e jurídico - acaba por ser determinante também no campo da Saúde do Trabalhador tendo em vista os embates freqü en tes que se estabel ecem en tre essas áreas.

Do lado dos trabalhadores, por sua vez, observa-se que muitos parecem se sen tir mais autorizados a buscar a assistência no CRST qua ndo se ressentem de probl emas de ordem física, sendo rara a sua ocorrência em situações em que eles apresen tem uma demanda dara e inicial de probl ema de saúde mental. Destacam-se a qui dois dos casos que demandaram assistência no CRST por esse motivo. O primeiro é o de um trabalhador de cerca de 40 anos que era responsável pela expedição de produtos de uma grande empresa de alimentos. Ele procurou ajuda de um outro serviço de saúde após ter uma crise de ausência enquanto con duzia um carro e quase ter provocado um grave aciden te que envolveria sua esposa e filhos. Em avaliação realizada pelo médico daquele serviço foi verificado que esse trabalhador apresentava sintomas orgânicos (pressão alta, el etrocardiograma alterado) e psíqu i cos (insônia, irritabilidade, etc.) que pareciam decorrentes de estresse e foi-lhe su gerido que proc u rasse o CRST de Campinas. $\mathrm{Na}$ en trevista inicial, no CRST, ele associava diret a men te as caracterís ticas do seu trabalho como as causadoras dos seus probl emas de saúde, destacando a grande responsabilid ade associada à sua função e à jornada excess iva de trabalho. Segundo ele, du ra n te anos, era comum que trabalhasse por até vin te horas seguidas, com predominância do horário noturn o, em uma atividade que lhe exigia atenção constante. Aqui, daramente, se evidencia a importância da participação da or ganização do trabalho na vivência desses sintomas. Contudo, deve-se notar que a "autorização" para buscar a ajuda do CRST foi dada por um médico.

No caso de probl emas de saúde mental associados à convivência co tidiana com situações 
de risco no trabalho, parece agora haver uma n ova configuração, em bora con tinu em pre sentes em ramos como o da con s trução civil e o da indústria química (Bernardo, 2002). Atualmente, evidencia-se também a convivência com um outro tipo de risco: o ri s coà vida decorrente da violência por agressão. Esse foi o caso de um geren te de banco que procu rou o CRST de Campinas com diagn ó s ti co de síndrome do pânico que ele relacionava ao fato de ter sido vítima de assalto na agência em que trabalhava, evento que envolveu também o seqüestro de s eus familiares. Nesse caso, a demanda à assistência foi motivada após ter vivenciado episódio de tensão ex trema.

O que parece efetivamente "autorizar" o trabalhador a apresentar à assistência os problemas de saúde mental e trabalho atualmen te é a LER. Observa-se que os trabalhadores que demandam assistência ao CRST devi do a essas lesões, na ocasião da consulta, também relatam probl emas de saúde mental que relacionam ao trabalho. Importante notar que, muitas vezes, os sintomas de ordem psíquica - tais como depressão e ansied ade - eram, in clu sive, sentidos há mais tempo do que os sintomas osteomusculares e que, portanto, não seriam a ex pressão das repercussões psicossociais desse tipo de adoec i m en to (Sa to et al., 1993; Bern a rdo, 2003). Um outro aspecto a se ressaltar é que os trabalhadores que procuram tratamen to para LER costumam identificar os mesmos aspectos da or ganização do processo de trabalho como re spon sá veis tanto pela doença osteomuscular como pelos problemas de ordem psíquica (Borges, 2001; Ribeiro, 1997; Sato, 2003). Expressões como "ri tmo alu cinante", "trabalho incessante", "loucura", "de se spero" são usadas com freqüência pelos trabalhadores para expressar a intensid ade do sof rimento provoc ado por essas características da organização do trabalho.

A atividade de teleatendimen to parece ser um caso exemplar do que foi descri to acima. É uma ativid ade que vem seexpandindo extra ordinariamente nas últimas décadas devido, sobretudo, à necessidade de as empresas manterem con $\mathrm{t}$ a to mais direto com seus cl i en tes e pode ser considerada uma sucessora da profissão de tel efonista. Em geral, a tarefa dos tel eoperadores consiste em atendimen to telefônico simultâneo à operação de terminal de computador. Apesar de a relação en tre as características dessa ativid ade com a ocorrência de problemas de saúde mental já terem sido bastante discutidas (Sznelwar \& Zidan, 2000), também nesse caso, é ra ro que os trabalhadores procurem ajuda devido a queixas relacionadas à esfera psíquica. No CRST de Campinas, os tel eoperadores ch egam ao serviço de saúde expressando apenas a queixa de LER e é somen te quando são indagados a respeito das causas que atribu em a seus sintomas - a tensão viven ci ada cotidianamen te pelas situações de pressão, pela falta de auton omia e pelo con trole exce s s ivo no trabalho - que referem, comu men te, a existência de sintomas de ordem psíquica, tais como depressão, insônia, desequilíbrio emocional etc. Observa-se, assim, que alguns dos problemas identificados entre as telefonistas por Le Guillant (1984), na década de 1950, não só se reprodu zem no caso do teleatendimento, mas também se ampliam com a intensificação do trabalho e a sofisticação do con trole propiciado pela tecnologia microel etrônica.

Finalmente, no que diz respei to a sintomas neuropsíquicos rel acion ados a intoxicações por produtos químicos no trabalho, o principal aspecto que pode ser con si derado uma mudança é o fato de haver maior conhecimen to e reconhecimen to dos sintomas neuropsicológicos como indicativos de intoxicação por produtos químicos. Verifica-se que os trabalhadores com diagnósticos dessa esfera, que são acompanhados pelo CRST de Campinas, quase que invariavelmen te foram encaminhados por outros s erviços de saúde e sindicatos ou foram iden tificados em ações de vigilância em ambi en te de trabalho realizadas pelos profissionais de saúde do trabalhador. Esse encaminhamento no entanto, não significa que os trabalhadores não associassem seus sintomas a produtos químicos, pois muitos deles, ao serem atendidos no CRST, afirmavam estabelecer essa relação. Contudo, diante da negativa do nexo com o trabalho, freqüen temen te apresentada pelos serviços médicos das empresas ou pelos médicos dos convênios de saúde, os trabalhadores se vi ram sem ação até a iniciativa do Sindicato ou da Vigilância em Saúde para uma verificação mais apurada dessas situações.

\section{A Saúde Mental e Trabalho pela perspectiva dos sindicatos}

Para alguns sindicatos de trabalhadores, atentos às questões de saúde do trabalhador, os problemas de saúde mental relacionados ao trabalho são cada vez mais ob servados. No que diz respeito à organização do processo de trabalho, a situação dos metalúrgi cos parece ser 
um bom exemplo. Apesar de as LERs serem, ainda, a principal doença do trabalho identific ada nos trabalhadores da categoria, Paulo Sérgio Gomes, diretor de saúde do Sindicato dos Metalúrgi cos da região de Campinas, já apresenta uma grande preocupação em relação ao crescimento das queixas de estresse. Em uma en trevista e esse respeito, ele diz o seguinte: Estou há três anos no Sindicato e, em todos esses três anos (...), eu fiquei trabalhando na saúde e de lá pra cá, logo de início você observa, né? Eu fui cipeiro, vice-presidente de CIPA, por duas gestões (...) e, aí, a gen te já ob serva, vem acompanhando dentro da fábrica e, depois, aqui no Sindicato Vê que vem intensificando as doenças mentais. A gente percebe alguns distúrbios, que an tes não eram vistos na fábrica, você começa a observar que os trabalhadores estão começando a desenvolver esses tipos de distúrbio. [o quê?] Estresse! O diagnóstico... a maioria das pessoas, quando você vai conversar diz que está... que é estresse.

As qu eixas apresentadas pelos trabalhadores são, segundo ele, os distúrbios do sono e a dificuldade em "organizar as idéias": Eles procuram você, você está ligado na área de saúde, tá no sindicato, eles falam: "oh, eu não consigo dormir à noite, eu não consigo mais...", às vezes tá estudando, "antes, eu estudava, assimilava tão bem, agora, tenho que ler cinco ou seis ve zes uma coisa simples pa ra pod er abstrair 30 ou 40\%...”.

Paulo avalia que esse problema tem tido ocorrência cre scen te en tre os metalúrgicos devido às mudanças nos sistemas de produção inspiradas no modelo japonês, que impõem uma intensificação marcante do ritmo de trabalho e uma carga de responsabilidades aos trabalhadores que ultrapassa a simples execução de uma tarefa. Ainda, segundo ele, o desemprego é um fator de pressão adicional sobre o trabalhador para que acei te se su bm eter a s i tuações de trabalho desumanas.

Já o Sindicato dos Químicos dessa mesma região - a qual, vale lembrar, é um dos mais importantes pólos petroquímicos do país vem lut a ndo para demonstrar a contaminação de trabalhadores por produtos químicos utilizados nos processos de produção de diversas empresas da sua base. Muitos desses produtos têm efeitos neurotóxicos e podem provocar sin tomas que são facilmen te confundidos com probl emas de saúde mental de ori gem psicodinâmica e, assim, tra tados erron eamente. Desse modo, o nexo com o trabalho é fundamental para que os trabalhadores que apre sentam dis- funções neu ropsíquicas recebam atendimen to adequ ado.

\section{A vigilância em saúde e as questões de Saúde Mental e Trabalho}

As avaliações do sindicato dos químicos e do sindicato dos metalúrgicos de Campinas apresentadas acima coincidem com aquilo que é observado pelos profissionais do CRST de Campinas em vigilâncias nas em presas do município. Os ris cos para a saúde mental dos trabalhadores, sejam aqu eles rel a tivos à organização do trabalho, à convivência com situações de perigo ou à contaminação por produtos químicos, não só persis tem como importantes problemas de saúde pública, como têm se agravado sen sivelmen te do pon to de vista da vigilância em saúde .

Esse é, particularmente, o caso dos fatores rel acionados à organização do trabalho. O ritmo acel erado, a pressão por produção, os con strangimen tos cotidianos e a ameaça de des emprego são observados em quase todas as empresas submetidas à vigilância pelo CRST de Campinas. A intensificação do ritmo é tal que os trabalhadores não têm tem po para conversar com os profissionais que atuam na vigilância. Esses aspectos parecem estar cada vez mais naturalizados nos processos de trabalho, com a alegação por parte das empresas de que elas não têm outra opção, pois também sofrem pressões do "m erc ado".

Esses probl emas não afetam somente o setor industrial - on de, aliás, é cada vez mais comum ouvi rem-se rel a tos dos trabalhadores sobre a total impossibilidade de atender necessidades humanas básicas durante a jornada de trabalho, tais como beber água ou ir ao banheiro - mas também estão intensamente presentes no setor de serviços. Além do caso já citado do teleatendimento, os serviços terceirizados que, em geral, não contam com sindicatos atuantes - também têm apresentado ocorrência crescente desse tipo de situação, o que é agravado com o aumen to de atividades realizadas no período noturno. A oferta de serviços de atendimen to vinte e qu a tro horas ou até altas hora s da noi te tem aumentado sensivelm en te em diversos setores, o que afeta não só os trabalhadores diretamente envolvidos, mas também outros, como os profis si onais de limpeza e manutenção que con cen tram suas atividades na madrugada, como é o caso dos shopping centers. 


\section{Saúde Mental e Trabalho e o contexto atual}

A vis ada sobre os problemas de Saú de Mental e Trabalho tomando-se como pon to de partida um serviço público de saúde do trabalhador permi te ob s ervar, como anu n ciado de s de o início, a persistência dos probl emas descri tos de sde meados da década de 1980. Em primeirolugar, di ferentes realidades se apresentam: olhando a partir da assistência, em termos numéricos é insignificante a atribuição, como prim eiro diagnóstico, de distúrbio mental; tal realidade se modifica quando se toma a LER como diagnóstico, a qual parece funcionar como uma espécie de fachada para que os problemas de saúde mental sejam levados à assistência; por o utro lado, tomando-se as informações angariadas tanto nas ações de vigilância como as provenientes dos sindicatos de trabalhadores, a realidace se apre s enta de outro modo.

Ao se comparar o acú mulo de con h ecimentos e informações existen tes há 20 anos e hoj e, sobre o tema Saúde Mental e Trabalho, não se pode negar que, atualmente, a produção técnico-científica na área experimentou crescimento, oferecen do elem en tos no sen ti do de fortalecer os argumentos e socializar o deb a te acerca da importante participação das condições e da organização do trabalho na vivência dos problemas de saúde/doença mental. Ao mesmo tem po, mostra n do com porta men to semelhante, verifica-se o espraiamen to dos serviços públ i cos diri gi dos aos trabalhadores, na qualidade de trabalhadores, os quais também teriam papel de fortalecer a con s trução do pon to de vista da Saúde do Trabalhador sobre a determinação e causalidade dos fen ô menos com os quais trabalha.

De outro lado, as recen tes e profundas mudanças na realidade de trabalho têm tido papel fundamental na con formação de um con texto po u co favor á vel à explicitação dos problemas de saúde mental e trabalho. Tais mudanças articuladas pelos fenômenos da gl obalização e da reestrutu ração produtiva no con tex to neoliberal (Ianni, 1993; Giraud, 1998; Borón, 1995; An ders on, 1995; Beynon, 1997; Antunes, 1997; 1999; Ramalho, 1997; Rodrigues, 1997; Arbix, 1997) - implicaram o enfraquecimento dos sindicatos, o seqüestro da promessa de cidadania expressa na Constituição Federal de 1988 (Werneck Viana, 2000; Soares, 2003) e o aumento sempre crescen te do desemprego e do trabalho não regula mentado pela CLT.
Se o desemprego é um dos problemas que conformou a área de Saúde Mental e Trabalho, assim o foi considerado principalmente pelos efei tos deletérios que produz àqueles que não con s eg u emse inserir em uma atividade produtiva. Entretanto, atualmente, ele também gera conseqüências para a saúde mental daqueles que trabalham.

Altas taxas de desemprego acompanhadas de uma maior exigência sobre aqueles que se candidatam a em prego - como ocorre em rel ação ao nível de escolaridade - e sobre aqueles que estão trabalhando, os quais devem estar sempre demonstra n do dedicação total às empresas são alguns dos aspectos que configuram o contex to denominado por Boltanski \& Chiapello (1999) de "o terceiro espíri to do capitalismo".

O desemprego crescente assume, então, uma faceta importan te como con trole simbólico. A força de todas essas mudanças, notadamente sua forte vinculação com a situação e o "fantasma" do desemprego, é sentida como imobilizadora da ação articulada dos indivíduos e também dos sindicatos. Ta lvez seja essa uma das expressões do que Forrester (1997) denomina de "violência da calma", em que a calma dos indivíduos e das sociedades é obtida pelo exercício de forças coercitivas antigas, subjacentes, de uma violência e de uma eficácia tal que passa despercebida. Essa "calma" ganha reforços simbólicos mediante o intenso espraiamen to e a articulação cristalizada do "discurso da competência” - versão popularizada da ideologia gerencial - que deposita no indivíduo a causa de "todos os males" e, conseqüentemente, a fonte de todos os remédios (Guimarães, 2003; Bendassolli, 2000/2001), abordando, assim, o já conhecido discurso que culpabiliza a vítima (pelo aciden te de trabalho, pela doença do trabalho, pelo de sem prego). Basicamente, tal discurso se caracterizaria, dentre outras coisas por,

Fazer o indiv í duo gerir responsabilidades privadas pela con dução da própria vida profissional. Isso implica no (sic) seguinte: o indivíduo tem de bancar os custos de sua formação profissional; ele tem de avaliar-seperiodicamente para ver se está adequado às regras e exigências que o mercado demanda dele.

Desmantelar a confiança, tanto em ações tomadas em conjunto, visando a interesses públicos, quanto na ação e eficácia do Estado pa ra gerir as dificuldades ou conflitos da sociedade (Bendassolli, 2000-2001).

E, express ando a força dessa realidade concreta, assim testemunha Pérsio Dutra (Peni- 
nha), diretor do Sindicato dos Trabalhadores em Processamen to de Dados do Estado de São Paulo:

Eu vejo, por exemplo, trabalhadores que têm pl ena consciência do mal que o trabalho the causa-eu estou falando de coisas que se refletem no ambiente psico sso cial do trabalho que é apressão da chefia, aquele medo do desemprego, fazer hora extra sem cobrar, porque tem banco de horas e "vamos nessa po rque precisamos vestir a camisa da empresa" - justamen te pa ra não perd er o emprego se calam; é aquela situação da pes soa estar trabalhando com dor e não ir ao médico porque ele não pode se afastar, porque senão vai ficar sob a mira do capataz e ai é "ir pr'o olho da rua". É tudo isso aí e que ele, na realidade, não deixa de conhecer, mas ele simplesmente [faz de conta]. (...) É, e de sindicato eu, trabalhador, só vou querer saber depois que eu for demitido, po rque senão "aqueles malucos [os sindicalistas] lá, vão atrapalhar a minha vida! (Pérsio Dutra [Pen inha], 2002).

Se, antes, trabalhar sob a regulamentação da CLT ou o sob o regime dos servidores públicos era um direi to, hoje, a qu ele que tem a "carteira de trabalho assinada" é um privilegiado. Como afirma Boi to Jr. (1999): Antes, cada trabalhador via no direito conquistado por outro um primei ro passo para que ele próprio conquistasseo seu; hoje, o trabalhador tende a ver no direito conquistado por outro um privilegio que ameaça seus próprios direitos. Exemplificando: até 1964, a estabilidade do funcionalismo público era um estímulo à luta do trabalhador do setor privado para obter, também, algum tipo de estabilidade no emprego (...). Hoje, a mesma esta bilidade do funcionalismo não é vista como objetivo a ser atingido por todos, mas como privilégio de pou cos a ser revogado.

$\mathrm{O}$ enfraquecimen to na mobilização dos trabalhadores desde o avanço das políticas neoliberais na década de 1990 (Boi to Jr., 1999) se reflete diretamente na sua atuação em relação à saúde. Esse fato é particularmente observável em relação a probl emas cuja ori gem está na or ganização do processo de trabalho, como é o caso de grande parte dos probl emas de saúde mental e trabalho.

Nessas condições, talvez uma das características importantes no que se refere à saúde dos trabalhadores seja a de que eles têm con dições de recon h ecer as situações de ris co do trabalho para sua saúde, mas não têm ti do outra opção que a submissão a tais condições. É comum, atualmente, o uvi r-se que quem tem um emprego, não importa qual, já pode ser con siderada uma pessoa de sorte. Essa submissão conscien te a condições inadequadas, particularmen te no que diz respeito ao ritmo de trabalho e às pressões cotidianas, parece estar se tornando um fator adicional de sofrimen to psíquico que merece uma atenção especial da área de Saúde Mental e Trabalho.

Esse con texto, portanto, mostra-se pouco propício para que o discurso da Saúde do Trabalhador tenha força argumentativa, cedendo espaço para que a visão alinhada ao discurso da Saúde Ocupacional/Medicina do Trabalho recrudesça. Aqui, vale recuperar o estu do desenvo lvi do por Lacaz (1996), que tomou como ob$\mathrm{j}$ eto de estudo as formações discurs ivas da academia, dos serviços e dos órgãos sindicais sobre as relações Saú de e Trabalho, mostran do as d i ferenças en tre o discurso da Sa ú de Ocupacional/Medicina do Trabalho e o da Sa ú de do Trabalhador. Se o da Sa ú deOcupacional/Medicina do Trabalho deve sua emergência no con tex to do processo de industrialização brasileira, vindo ao encon tro da necessidade de controlar a força de trabalho, sustentando-se em uma visão funcionalista e individualizante, a Sa ú de do Trabalhador é for jada no con tex to do ressurgimen to do movimen to sindical no Brasil no final da década de 1970 e buscou nas relações de trabalho a determinação do processo saúdedoença. Con forme Lacaz (1996), tais discursos estão em relação dinâmica, lutan do por posições centrais no campo científico (Bourdieu, 1983) e devem sua força argumentativa não a eles mesmos, mas às condições concretas em que se inserem.

A persistência dos problemas de Saúde Mental e Trabalho pode ser com preendida nos moldes propo stos por Lacaz (1996): o con texto a tual congrega duas tendências opostas. De um lado a existência de conhecimentos acumulados sobre o tema e, de outro, o "tercei ro espírito do capitalismo", con forme Boltanski \& Chiapello (1999), que propicia a hipertrofia do disc u rso da culpabilização da vítima. 


\section{Colaboradores}

L Sa to e MH Ber nardo participarm igualmente de todas as etapas de elaboração do artigo.

\section{Referências bibliográficas}

An ders on P 1995. Balanço do neo liberal is m o, pp. 9-23. In E Sader \& P Gentili (orgs.). Pós-neoliberalismo - as políticas sociais e o Estado democrático. Editora Paz e Terra, São Paulo.

An tunes R 1997. Trabalho, ree s trutu ração produtiva e algumas repercussões no sindicalismo brasilei ro, pp. 71-85. In R An tunes (or g.). Neoliberalismo, trabalho e sindicatos - reestrutu ração produtiva na In glaterra e no Brasil. Boitempo Editorial, São Paulo.

Antunes R 1999 Os sentidos do trabalho: ensaio sobre a afirmação e a negação do trabalho. Boi tem po Editorial, São Paulo.

Arbix G 1997. Os descaminhos do governo e a precarização das relações de trabalho, pp. 480-502. In L Carleial \& R Valle (orgs.). Reestruturação produtiva e mercado de trabalho no Brasil. Hucitec-ABET, São Paulo.

Bendassolli PF 2000-2001. Ovocabulário da habil i d ade e da com petência: algumas considerações neopra gmáticas. Cadernos de Psicologia Social do Trabalho 3/4: 65-76.

Bern a rdo MH 2002. As representações dos trabalhadores s obre os riscos em uma usina química. Cadernos de Psicologia Social do Trabalho 5:1-18.

Bern a rdo MH 2003. Grupos terapêuticos para trabalhadores com LER/DORT: a experiência de Campinas, pp. 91-93. In MABC Takahashi \& RG Vilela(or gs.) A saúde do trabalhador e saúde ambiental: cenário, experiências e perspectivas. Editora PMP, Piracicaba.

Bertolli-Filho C 1992-1993. Medicina e trabalho: as "ciências do comportamen to" na década de 40. Revista de História 127-128:37-51.

Bey n on H 1997. As práticas do trabalho em mutação, pp. 9-38. In R An tunes (org.). Neoliberalismo, tra balho e sindicatos - reestrutu ração produtiva na In glaterra e no Brasil. Boitempo Editorial, São Paulo.

Boito Jr A 1999. Política neoliberal e sindicalismo no Brasil. Ed. Fora da Ordem, São Paulo.

Boltanski L \& Chiapello E 1999. Le nouvel esprit du capitalisme. Gallimard, Paris.

Bor ges LH 2001. As lesões por esforços repetitivos (LER) como índice do mal-estar no mundo do trabalho, pp. 157-174. In LH Borges, MGB Moulin \& MD Araújo (orgs.). Organização do trabalho e saúde - múltiplas relações. EDUFES, Vitória.

Borón A 1995. A sociedade civil depois do dilúvio neoliberal, pp. 63-118. In E Sader \& P Gen tili (orgs.). Pósneoliberalismo - as políticas sociais e o Estado democrático. Editora Paz e Terra, São Paulo.

Bourdieu P 1983. O campo científico, pp. 122-155. In R Ortiz (org.). Pierre Bourdieu: sociologia. Editora Ática, São Paulo.

Chaui M 1993. Conformismoeresistência. As pectos da cultura popular no Brasil. Brasiliense, São Paulo.

CRST-Campinas 2004. Siamap 2K. Campinas.
Figuei redo LC 2002. Matrizes do pensamento psicológico (9a edição). Vozes, Petrópolis.

Figu ei redoLC \& Sa n ti PLR 2000. Psicologia-uma (nova) introdução. Uma visão histórica da psicologia como ciência. Educ, São Paulo.

Forre s ter V 1997. O horroreconômico. Editora da Universidade Estadual Paulista, São Paulo.

Giraud PN 1998. A desigualdade do mundo - a economia do mundo con temporâneo. Terramar Editores, Distribuidores e Livreiros Ltda, Lisboa.

Guimarães EV 2003. Executivos em revista-disc u rsos de e pa ra executivos e aspirantes a executivos. Dissertação de mestrado. Programa de Pós-Graduação em Psicologia Social, IP-USP, São Paulo.

Ianni O 1993. A so ci edade global. E d i tora Civilização Brasileira, Rio de Janeiro.

Lacaz FAC 1996. Saúde do Trabalhador: um estudo sobre as formações discursivas da Aca demia, dos Serviços e do Movimento Sindical. Tese de doutorado. Faculdade de Ciências Médicas. Unicamp, Campinas.

Lacaz FAC 1997. Sa ú de dos trabalhadores: cenário e de s afios. Cadernos de Saúde Pública 13(supl. 2):7-19.

Le Guillant L 1984. A neu rose das telefonistas. Revista Brasilei ra de Saúde Ocupacional 47(12)7-11. Tradução de La névrose des téléphonistes, La Presse médicale, 1956.

Mi n ayo Gomez C \& Thedim-Costa SMFT 1997. A construção do campo da saúde do trabalhador: percurso e dilemas. Cadernos de Saúde Pública 13(supl. 2):21-32.

Oddone I et al. 1986. Ambiente de tra balho: a luta dos trabalhadores pela saúde. Trad. Salvador Obiol de Freitas. Hucitec, São Paulo.

Ramalho JR 1997. Prec a rização do trabalho e impasses na organização coletiva no Brasil, pp. 85-114. In R Antunes (org.). Neoliberalismo, trabalho e sindicatos - reestrutu ração produtiva na Inglaterra e no Brasil. Boitempo Editorial, São Paulo.

Rebouças A JA et al. 1989. Insalubridade. Morte lenta no trabalho. Diesat/Oboré, São Paulo.

Ribeiro HP 1997. Lesões por Esforços Repetitivos (LER): uma doença emblemática. Cadernos de Saúde Públ ic a 13:85-93.

Ribeiro HP et al. 2002. Herval Pina Ribeiro, Francisco Antonio de Castro Lacaz, Carlos Aparício Clemen te e Pérsio Dutra falam sobre a história do DIESAT (Entrevista com Leny Sa to). Ca dernos de Psicologia Social do Trabalho 5:63-85.

Rodrigues IR 1997. Sindicalismo, em prego e relações de trabalho na indústria automobilística, pp. 115-129. In R An tunes (org.). Neoliberalismo, trabalho e sindicatos - reestruturação produtiva na Inglaterra e no Brasil. Boitempo Editorial, São Paulo.

Sa to L 1996. Trabalho e Saúde Mental, pp. 169-175. In Central Única dos Trabalhadores. Saúde, Meio Am- 
bi en te e Condições de Trabalho - co n teúdos básicos para uma ação sindical. CUT, São Paulo.

Sa to L 2003. Subj etividade, saúde mental e LER, pp. 6180. In RC Ruiz (org). Um mundo sem LERépossivel. UITA (União Internacional dos Trabalhadores da Alimentação), Montevidéo.

Sa to L, Araújo MD, Udihara ML, Franco FN, Daldon MTB, Settimi MM \& Silvestre MP 1993. Atividade em grupo com portadores de L.E.R. e achados sobre a dimensãopsicossocial. Revista Brasilei rade Saúde Ocupacional 79(21):49-62.

Sa to L, Lacaz FAC \& Berna rdo MH 2004. Psychology and Workers' Health Movem ent in the State of São Paulo. Journal of Health Psychology 9(1):121-130.

Sa to L \& Seligmann-SilvaE 1986. Saúdemental: as diversas expressões. Tra balho \& Saúde (órgão informa tivo do DIESAT), ano 15:38- 40.

Seligmann-Silva E 1986. Crise econô mica, trabalho e saúde mental, pp. 54-132. In VA An gerami (org.). Crise, trabalho e saúde mental no Brasil. Traço, São Paulo.
Seligmann-Silva E 1994. Desgaste mental no trabalho dominado. Editora UFRJ, Rio de Ja n eiro; Cortez Editora, São Paulo.

Seligmann-SilvaE 1997. A interface desem prego prolongado e saúde psicossocial, pp. 19-64. In JF FerreiraFilho \& S Jardim (org.). A danação do tra balho - organização do trabalho e sofrimento psíquico. Te Corá Editora, Rio de Janeiro.

Shartle CL 1950. In du strial psychology. Annual Revi ew of Psychology vol. 1:151-172.

Soa res LT 2003. O desastre social. Editora Record, Rio de Janei ro-São Paulo. (Os porquês da desordem mundial - mestres explicam a globalização).

Sznelwar LI \& Zidan LN (or gs.) 2000. O trabalho humano com sistemas informatizados no setor de serviços. Plêiade, São Paulo.

Werneck-Vianna MLT 2000. A americanização (perversa) da seg u ridade so cial no Brasil: estra té gias de bem-estar e políticas pública. UCAM, Iuperj, Rio de Janeiro.

Artigo apre sent ado em 17/06/2005

Aprovado em 28/07/2005

Versão final apre sent ada em 28/072005 